\title{
Shifting the Evaluative Gaze \\ Community-based program evaluation in the homeless sector
}

\section{Bruce Wallace \\ Bernadette Pauly Kathleen Perkin}

Mike Ranfft

Victoria Cool Aid Society
Gateways: International Journal of Community Research and Engagement Vol 8/No 1 (2015): 43-58 (C) UTSePress and the authors

ISSN 1836-3393
University of Victoria

Poverty and lack of safe, affordable housing are growing problems in Canada (Gaetz et al. 2013). Recent estimates found that more than 235000 individuals use emergency shelters in a given year (Gaetz, Richter \& Gullivan 2014). Homelessness is a result of a series of policy failures including withdrawal of government from social housing and failure of the private market to build affordable housing (resulting in rising housing costs and low vacancy rates), as well as decades of regressive welfare reforms (Bryant et al. 2011; Eberle et al. 2001; Hulchanski 2009; Shapcott 2009; Wallace, Klein \& Reitsma-Street 2006). At the same time, gentrification and loss of ageing housing stock, along with health-care reforms, including deinstitutionalisation, have exacerbated these problems, leaving many people without adequate housing (Quigley \& Raphael 2001; Shapcott 2009). The consequence is growing inequities that adversely impact those experiencing or at risk of homelessness, including increasing physical, mental, emotional and oral health disparities when compared to the rest of the population (Frankish, Hwang \& Quantz 2005; Hwang 2001, 2010). Further, there is a risk of premature death among those who are homeless, with people dying at a much younger age than the rest of the population (Hwang et al. 2009).

In many Canadian cities, non-governmental organisations (NGOs) initiate and provide the majority of programs mounted as part of the response to homelessness. These agencies face increasing demands for information about the outcomes and cost-effectiveness of their programs. It is within this context that housing providers in one Canadian city identified the need for a research plan that could integrate evaluation as part of a transitional shelter program development and operation. The NGO initiated a partnership with local researchers to conduct an evaluation that would provide information about the effectiveness of this program in ending homelessness.

In this article, we examine the application of communitybased research (CBR) principles and practices in the homeless sector and the implications for the production of knowledge and social change to address homelessness. Drawing on our 
experiences as researchers and service providers, we reflect on the significant successes and challenges associated with using CBR in the homelessness sector. We describe CBR and its potential as a methodological framework for participatory program evaluation and social change. Briefly, we describe the transitional shelter program that was the focus of our CBR program evaluation and discuss the benefits and challenges of CBR implementation based on our experiences conducting this program evaluation. Finally, we discuss lessons learned and implications for future CBR research in the homelessness sector.

\section{COMMUNITY-BASED RESEARCH: OVERVIEW OF LITERATURE}

Community-based research, sometimes known as communitybased participatory research (CBPR), is a collaborative approach to research in which partners from a variety of contexts work together on all aspects of the research in an equitable way with an aim of democratising knowledge (Israel et al. 1998). A communitybased research partnership often includes one or more academics, representatives from community organisations and community members. A fundamental characteristic of community-based research is 'the participation and influence of non-academic researchers in the creation of knowledge' (Israel et al. 1998). This is central to democratising the processes of knowledge production (Reid, Brief \& LeDrew 2009), through valuing and utilising the knowledge and experiences of the stakeholders, especially those with less power and resources in the research process (Green \& Mercer 2001).

CBR has the potential to effectively integrate the theoretical and methodological academic expertise of researchers with the community participants' expertise and experiential knowledge of the research issues and findings (Cargo \& Mercer 2008). Thus, community-based research is not simply about engaging in research with community partners or having community as a site for research, but rather about researchers and community partners as co-producers of knowledge to achieve common goals through power sharing (Israel et al. 1998). The participation of community is assumed at all steps in the research, and engagement should be a long-term and sustainable process (Minkler \& Wallerstein 2008). Indeed, an expected outcome of the CBR process is colearning between partners and mutual benefits for community and researchers (Israel et al. 1998). CBR has an explicit social justice mandate and includes social action as one part of the research process (Strand 2003). Therefore, CBR is concerned with participation and knowledge development to empower and/ or generate actions to effectively translate knowledge in order to change or improve policies and programs through critique of broader power structures, as part of the research process (Lazarus et al. 2012; Wallerstein \& Duran 2008). 
While CBR holds the potential to produce more applicable research than traditional researcher-driven approaches (Minkler \& Baden 2008), there are challenges associated with conducting CBR. Lazarus et al. (2012) identify several inherent tensions experienced in CBR, including tensions between science and community participation, science/research and practical goals/action, and control over phenomena and collaboration continuum. More specifically, participation and social action are often stated in ideal terms that fail to engage with power dynamics. As well, there are challenges to the implementation of rigorous but flexible research designs and difficulties in navigating research team roles and responsibilities due to conflicting demands and timelines. Those conducting CBR need to be aware of these challenges and have the skills to balance the often competing demands of participation, rigour and real-world complexities, while maintaining a commitment to and enacting social action (Springett \& Wallerstein 2008).

\section{BACKGROUND: THE RESEARCH SITE}

Victoria is the capital of the province of British Columbia, Canada, with approximately 363000 residents living in the city and surrounding areas (Statistics Canada 2013). Victoria Cool Aid Society (Cool Aid) is one of the NGOs responsible for most of the region's emergency shelters and 374 units of supported housing, as well as a community health clinic including health and dental services. In the mid-2000s, staff and managers with years of experience working in emergency shelters noticed that, while the main emergency shelter provided essential services, the sometimes chaotic setting was not conducive to more concentrated, uninterrupted support for clients. To address this issue, Cool Aid decided to implement a model of transitional shelter which was more focused on one-on-one support in the hope that this would help some people make a more permanent transition out of homelessness. Although the Greater Victoria Coalition to End Homelessness had adopted Housing First as its primary philosophy in addressing homelessness (City of Victoria 2007; Tsemberis \& Eisenberg 2000), it was clear to housing providers that the lack of available housing, as evidenced by low vacancy rates and high costs, would make it extremely difficult for individuals to move directly into housing from the emergency shelter (Pauly et al. 2011, 2013).

While overall rental vacancy rates have increased, vacancy rates for bachelor suites and housing with rents less than $\$ 700$ a month are extremely low (Canada Mortgage and Housing Corporation 2012). In Victoria, approximately one in four renters are in core housing need, paying over 30 per cent of their income on housing costs, and over 10 per cent are in severe housing need, paying more than 50 per cent of their income on housing (Canada Mortgage and Housing Corporation 2010, 2011, Pauly et al. 2013). 
In February 2008, Cool Aid opened a transitional shelter program, a 15-bed facility available to both male and female clients over the age of 18 with a history of emergency shelter use. The transitional shelter provides a home-like setting in a renovated rooming house where bedrooms are shared. Residents share common living areas and contribute to the cooking, cleaning and yard work. The transitional shelter is staffed 24 hours a day, with two staff members on shift at all times and additional staff who do outreach, including assessments and follow-up, during the week. Residents do not pay rent, and are provided with meals. Recreation passes and bus passes are also available.

The primary mandate of the transitional shelter is to provide temporary accommodation for emergency shelter clients where staff can work closely with residents on personal action plans with a goal of moving clients into more stable housing. The aim of the program is to reduce recidivism to homelessness and emergency shelters. A high staff to resident ratio and the absence of drop-in services enable staff to work more intensively with residents. The program is set up to ensure that each resident who leaves has community supports in place so that, in a crisis situation, supports are available to assist them to maintain their housing. The program has four key goals for a successful transition to stabilised housing:

1 An appropriate, affordable, long-term housing situation

2 An income adequate to maintain self and housing

3 Increased overall health and wellbeing including access to appropriate health-care services

4 The appropriate supports to live independently.

At the onset of the program, the transitional shelter was considered 'dry' housing. Use of alcohol and other drugs was not permitted while in the program and individuals admitted to the program had goals that included sustained recovery from substance use problems. However, relapses to substance use are recognised as part of recovery and tolerated as long as the substance use does not negatively impact other residents. Funding for the program required that it be a low-barrier shelter. Cool Aid's philosophy is informed by the belief that residents should have access to both wet-housing and dry-shelter options. Since Cool Aid operates several low-barrier shelters that tolerate drug and alcohol use, this program was originally designed to provide an alternative for those individuals wishing to live in an environment without drugs and alcohol. However, that has evolved over years of program operation to a point where it is recognised that substance use may be a feature of clients' lives. As is consistent with a lowbarrier shelter, residents have access to harm-reduction supplies and may use drugs or alcohol as long as they do not interfere with their recovery goals or those of other clients. 
Below, we reflect on the implementation process of the community-based program evaluation and highlight aspects that we found significant or surprising in what has been a highly rewarding and productive partnership from the perspective of both university and community research partners. We also outline some of the challenges related to participation and power-sharing in the research process and flexibility of the research design, and discuss the challenges related to implementation of the data collection and ethics processes necessary for conducting rigorous research and achieving social justice aims.

PARTICIPATION AND POWER IN THE RESEARCH PROCESS

A question central to CBR is: who is involved in the research process, and how (Lazarus et al. 2012)? A core principle of community-based research is that the research question should originate from the community (Minkler \& Wallerstein 2008). This may seem a minor factor, but this principle is crucial in the establishment of relationships and as a guide to the research process. In our situation, as the transitional shelter program was being developed, the staff recognised the need for research and evaluation. In the early stages of the project, the program staff contacted a community-based researcher (Wallace). He had many years' experience working in the non-profit sector and with shelter staff (Ranfft). As the physical structure of the house came together, the researcher and staff met on site mid-construction to put together a plan for evaluation that could be implemented from the start of the program.

The research questions came from staff as they developed the shelter, and the staff played an equally critical role in developing the evaluation plan. As the evaluation took shape, additional academic collaborators joined the research team. The community-based researcher (Wallace) contacted an academic researcher (Pauly) who was already engaged in community action on homelessness and substance use issues.

Participation is integral to CBR, but it is critical to question how much a community actually wants or needs to participate in each aspect of a research project (Stoecker 2008). There is an inherent risk within participatory and community-based research of inadvertently problematising community participation by developing a research plan that seeks participation from research partners in the community without requiring a similar level of obligation for the researcher to participate in the community's priorities and activities. The problem, or challenge, with CBR is often conceived as convincing communities to participate in research. However, because CBR is not an end in itself, but rather a means for larger social change, the challenge can be reframed as how to engage researchers to participate in the larger context of the community and social change. Reviews of CBR projects by 
Minkler et al. (2008) describe how CBR's social justice mandate requires the activism of the researchers as well as the researchers' sustained commitment to and participation within the community.

In our evaluation project, the researchers' longstanding participation in the larger community context and their shared commitment to social justice and ending homelessness were just as critical as the community's participation in every stage of the research. As people not actually working at the shelter, the community-based and academic researchers (Wallace and Pauly) were in different ways outsiders in the transitional shelter. Bruce Wallace had many years of experience working with the street community and researching and writing about issues related to poverty and homelessness, including doing research with Cool Aid. He was able to play a key role in bridging the community and university because of his longstanding history with the organisation. Collaboration with academia was similarly seamless as the primary academic researcher (Pauly) was also engaged in addressing poverty and homelessness in the community, had conducted research with Cool Aid and, both as an academic researcher and volunteer, was a frequent speaker and advocate for ending homelessness. At the same time, her location in academia facilitated access to research funds and the engagement of collaborative researchers from the university.

In this project, the primary research partners included community and academic based researchers and the shelter providers of the transitional program. In homelessness research, social exclusion of those affected by homelessness is a key issue and inclusion is germane to the development of solutions to end homelessness (Norman \& Pauly 2013). Central to participation of those affected are questions about how to engage and include people with direct experience of homelessness in research. While the service providers initiated the research, it was the researchers who eventually raised the issue of inclusion of people with experience of homelessness in the process of doing the research. It is evident that service providers have important knowledge of the people that they serve and operate with the intention of wanting to improve conditions for the people they serve. However, given the power differentials between providers and clients, it is not always clear how to engage people with experience of homelessness directly in program development and implementation. In the third stage of the research project, two advisory groups were initiated as part of the ongoing research. One group was composed of additional frontline shelter staff and a second group directly engaged people with experiences of homelessness and use of transitional shelter. This allowed for greater participation in the research process, with the researchers facilitating both groups as a means of engaging the respective expertise of both groups in data collection, data analysis, and interpretation and communication of the findings. In the communication of the findings, both groups had an opportunity to work together on the recommendations. 
Power differentials were increasingly mitigated by the fact that many current residents became past residents during the project, shifting their relationships with providers.

\section{RESEARCH PRIORITIES AND GOALS}

For the shelter staff who had initiated the research, program evaluation was a priority on par with other functions of the transitional shelter, such as conducting intakes, planning meals or assisting residents with referrals. The importance accorded to evaluation continued through the project and contributed significantly to its success. In part, their interest in evaluation was motivated by an awareness that they were developing a new type of program and that they would need to demonstrate whether or not the program was cost effective and achieved the identified goals, including reducing recidivism to homelessness and emergency shelters and supporting permanent exits from homelessness. Both the community-based and academic researchers have a strong commitment to social justice and a theoretical perspective that draws on structural approaches to addressing health and social inequities, with a specific interest in and commitment to evaluating the effectiveness of different options for reducing homelessness.

Since the researchers were able to partner with the provider early in the program development, they had an opportunity to work with staff to mutually develop the research questions, data collection methods and instruments, and the processes for evaluation. In undertaking the evaluation, there was a unique opportunity to integrate data collection into transitional shelter programming as the program was being developed. The community and university researchers, as well as the service provider partners, saw this as a coordinated approach that would lead to respectful, unobtrusive research with the potential for social impact.

From the start, the goals of the community and academic researchers were to ensure that the research would be community relevant, effectively coordinated with service provision, and hopefully provide evidence of the program's effectiveness and new insights into the social policy context of homelessness. All partners shared an interest in developing a research process that could both provide accountability of the program and inform better systemic responses to homelessness. In order to meet these goals, a community-based research approach was chosen as the overarching framework for the evaluation, to address power inequities in the research process and promote social justice as an outcome.

\section{Flexibility and Tensions in Research Design}

Informing this decision was the knowledge that CBR may be combined with a broad range of qualitative and quantitative methodologies based on the goals and objectives of the research (Lazarus et al. 2012). Traditional program evaluations often focus 
on the individual and evaluate the program's success in changing individual behaviour (Pauly, Carlson \& Perkin 2012). However, factors such as affordable housing availability and welfare reform play a significant role in the success of transitional shelter programs. Acknowledging this reality requires an approach to program evaluation and theoretical frameworks that adequately capture the sociopolitical and economic context in which the resident and program are located. Thus, we sought to shift the focus from evaluating change at the individual level to examining the program and its participants within a larger sociopolitical and economic context in which there is and continues to be a scarcity of affordable housing.

Consequently, we drew on case study methodology (Yin 2009) within a community-based research framework. We deliberately chose a case study research design because we wanted to understand the transitional shelter program within its social, political and economic context so as to inform our assessment of the program's effectiveness (Pauly, Wallace \& Perkin 2014). According to Yin (2009), case study research is 'an empirical inquiry that investigates a contemporary phenomenon in depth and within its real-life context, especially when the boundaries between phenomenon and context are not clearly evident'. Case study methodology is valuable because of its flexibility and rigour, and it is often used to develop theory, evaluate programs and develop interventions (Baxter \& Jack 2008). Case study research involves multiple forms of data collection to facilitate the examination of broader social, political and economic factors (Yin 2009).

By drawing attention to these sociopolitical and economic conditions, we sought to shift the evaluative gaze to include the context in which the program operates (Springett \& Wallerstein 2008). With this shift in gaze, traditional criteria for success and failure of the program could be questioned, and the mandate for change could also shift towards changing the social conditions that create or reinforce inequities in power and access to resources. Several authors have observed that it is particularly important to consider the effects of social policies as part of evaluations of transitional housing programs (Barrow \& Zimmer 1999; Dordick 2002). Thus, program participants and the program are studied in context to determine what works for whom and under what conditions (Dunn et al. 2013; Pawson \& Tilley 1997).

Programs addressing homelessness are generally evaluated for their success on housing indicators alone; for example, the number and percentage of participants who exit into housing (Pauly, Carlson \& Perkin 2012). However, success measured in this way would be limited for transitional shelter participants in the context of market rental housing being unaffordable and income assistance rates too low, and where residents lacked access to health and social services required for overall health and wellbeing. For example, in the province of British Columbia, 
residents on all forms of income assistance receive only C $\$ 375$ a month for shelter costs and the average rent of a bachelor unit is around C $\$ 650$ a month (Pauly et al. 2013; Pauly et al. 2011). To be consistent with a social justice approach, we needed to select outcome indicators that reflected the social, political and economic conditions experienced by people in the transitional shelter. The program staff and the collaborating researchers were equally eager to develop indicators of success that went beyond the principal program mandate of reducing emergency shelter use or improving housing status so as to position the findings of the research in the broader sociopolitical context and inform social change. Together, we determined that indicators of success for the transitional shelter evaluation would measure outcomes in four integrated dimensions: (1) access to stable housing, (2) improvements in health and wellbeing, (3) access to adequate income, and (4) community inclusion, in alignment with program goals. Based on experience and knowledge of the literature, we identified these four dimensions as the main pieces of the jigsaw puzzle of housing stability. All four pieces are needed to create a stable foundation for clients to move out of homelessness.

Thus, in the development of the evaluation framework, we included attention to housing, income, health and social supports, reflecting an emphasis on key social determinants of health (Raphael 2009). This is in contrast to the usual measures of individual self-sufficiency which so often characterise evaluation of homelessness programs. This explicit framing of the evaluation framework in relation to the social determinants of health and the broader sociopolitical determinants that shape housing affordability and income fostered attention on issues of power and inequality and the way in which individuals and the program were structurally positioned in relation to larger societal inequities.

As part of the evaluation, we inventoried all social housing units that would potentially be available for single adults in Victoria. The preliminary findings of the social housing inventory revealed that there were essentially no vacancies in these units and that specific eligibility requirements made it difficult to access social housing. We found that the bureaucratic paths to social housing are often a maze, complex and difficult to navigate. For example, staff identified that in order to get into some social housing, individuals were required to have a case manager, but that many residents of the transitional shelter were ineligible to obtain a case manager due to restrictions on these services. Most transitional shelter clients needed expert assistance to find their way through a convoluted housing system with multiple providers, different sets of criteria for entry and long waiting lists. To simply focus on self-sufficiency would place the balance of responsibility on the individual for systemic failures, rather than place the efforts of individuals and programs into the context of these broader social conditions. 


\section{Burdens and Challenges of Data Collection}

One of the goals of the evaluation was to integrate data collection into the shelter operations to reduce the burden on staff and clients, as well as potentially inform program operations. In addition to data for the evaluation, it was necessary for transitional shelter staff to collect information on clients to screen potential residents, comply with two program funders' reporting requirements and plan for clients' needs while in the shelter. Once someone enters the shelter, they are interviewed by staff as a way to develop a personal work plan. In order to avoid duplication of effort and reduce the burden on transitional shelter residents, we tried to integrate evaluation data collection into the usual routines of the transitional shelter. We did develop separate data collection instruments for the evaluation, but removed any questions requesting information that was already collected as part of existing screening and intake procedures. Results from both processes were combined at the analysis stage. This efficiency would not have been possible without the direct involvement and input of shelter staff and managers.

In spite of our combined and concerted efforts, we were not always able to avoid duplication in data collection. As the research was being developed, the provincial funding agency for shelter programs instituted a new data collection and evaluation process that all agencies had to participate in as a condition of funding. The intentions of the provincial funder were admirable as they sought a standard reporting format for all shelters in the province and required shelter staff to follow up with clients. However, this change emerged after substantial collaboration among the research team to develop and implement data collection tools. As a result, the shelter staff were now presented with two research processes, often seeking the same information from residents, and this situation was contrary to our intention of integrating our research into the shelter data collection processes. In the end, we realised that the program had to adopt the mandatory data collection tools from the provincial funding agency, but supplement this process with our more in-depth data collection instruments and amalgamate the findings in our analysis.

We also encountered challenges integrating evaluation data collection with shelter intake and exit procedures. The original plan to use the surveys for both evaluation and program planning did not turn out as we intended. Moving from an emergency shelter into a transitional shelter can be an overwhelming experience for clients. In addition to our intake form, new residents are faced with a small stack of paperwork including several consent forms and another survey, all of which are required either by funders or to plan clients' care while in the program. To ease the transition, shelter staff developed an intake process that allowed residents to settle into the house first and then complete the paperwork over a few days or weeks. In response, we decided to redraft the surveys to remove the detailed case management questions and generally 
shorten the survey wherever possible, although we were left with the limitation of having intake surveys completed somewhat after the actual time of entry into the program.

In addition to the intake survey, we had an exit survey for residents to complete shortly before leaving the program. If entering a transitional shelter is a stressful transition, it seems that leaving it can be even more fraught, and clients generally were not completing the exit surveys. Some residents left because they were moving into housing, while others had to leave due to an emergency, or were asked to leave. Even under the most favourable circumstances, completing the survey was not a priority for residents or staff. Typically, 'bad' exits could not be foreseen, and so did not allow for surveying. This presented obvious problems for data collection, especially as it seemed like people leaving under 'good' circumstances would have more opportunity to fill out a survey, biasing our sample. The research risked capturing only the 'good' exits and not the 'bad', or not collecting any data at exits. To simplify this often complex and highly individual set of circumstances, two alternate strategies were developed: one was a $C \$ 20$ incentive for residents to complete the survey at (or soon after) exit; the other was the development of a staff completed Discharge Summary Evaluation - a simple instrument for staff to record basic outcomes on the most significant variables (housing, income, health, social supports) for all residents. This way we had some information on everyone who left the program, whether they left under 'good' or 'bad' circumstances.

\section{Communication of Research Processes}

One of the advantages of community-based research is that it can increase capacity among community organisations to conduct research. For this agency and program staff, program evaluation was clearly a priority. However, it cannot be assumed that all community partners come already prepared to conduct research in a way that conforms to current academic practices without significant support. We needed to use a consent form that conformed to the requirements of the University's Research Ethics Board, so we were unable to combine our consent process with any of the several other consent forms shelter residents had to sign. After an initial period of data collection, we discovered that university consent forms were not being completed and therefore many of the completed surveys could not be included in the analysis. We achieved a better success rate with the consent forms by emphasising their importance to staff and carefully tracking their completion. In our project, the research assistant (Perkin) would regularly (that is, weekly) go to the shelter to provide any necessary support, collect completed forms and ensure there were adequate honorariums and surveys for ongoing data collection.

The issue surrounding consent forms highlights a challenge for university-community partnerships. The forms were essential to academic interests but overlooked in a setting that had to be responsive to clients' basic needs as well as crisis situations. It was 
easy to miss our consent form among the several other forms that needed to be completed. Community-based research encourages an egalitarian approach where all partners contribute to knowledge creation and no one partner's position is privileged over the others. Just as community members have important knowledge about their contexts, researchers must also share their knowledge of research contexts and processes, like consent forms and data collection, in the interests of the research project's success.

\section{COMPETING TIMELINES AND REPORTING OF FINDINGS}

Community-university collaborations often struggle with competing timelines (Springett \& Wallerstein 2008). Both academic and community partners face competing external deadlines. External pressures such as funding application cycles, ethics reviews and publications dictate the university research schedule. At the same time, the community partner may be under pressure to produce program reports, while struggling to meet the constant everyday needs of clients. In our situation, there were minimal challenges with timelines as the researchers sought to fit their work to the transitional shelter's schedule. However, at the end of the shelter's initial year of operation, the staff were required to submit reports to their funding agencies. The researchers were unaware of the deadline and realised that staff were creating reports without the support of the data from the research project. The situation raised doubts from the researchers as to the usefulness of the research process if it could not be responsive to these demands for information. To remedy the situation, the researchers ran an analysis of the data to date and collaborated with staff on the funder report. The situation was a reminder that data collection and priorities vary for community partners and academic researchers. In this case, researchers and community agencies were working with different deadlines, with the researchers primarily focused on the research funding timelines and the community agency partners focused on program funder deadlines. Researchers need to be aware of deadlines relevant to the demands for data from a program's outside funding agencies while clearly communicating research timelines.

\section{CONCLUSIONS AND IMPLICATIONS}

In this climate of hyper-accountability, there are significant demands on community agencies in the homeless sector, and elsewhere, for program evaluation. Program evaluation is key for knowledge development in the homelessness sector. CBR is a unique and valuable approach to program evaluation in the homelessness sector to generate knowledge and social change through a collaborative research process. At the same time, there are challenges in the application of CBR principles and practices in the homeless sector. 
A CBR approach to program evaluation in the homeless sector has benefits when researchers are engaged in both community and activism to end homelessness. Just as participatory and community-based research values community participation in research, there is value in researchers' commitment to sustained participation in community. Because CBR is not an end in itself, but rather a means for larger social change, in addressing homelessness, there is a need to engage researchers to participate in this larger context of the community and social change.

Program evaluations can have a large social impact, but community-based research's foundation in social justice must inform all aspects of the research, including what measurements of success are used in the evaluation. Indicators of individual client successes and individual behaviour change, while compelling and attractive from a program funder perspective, do not capture the actual extent or causes of homelessness, nor do they give the context required to fully understand whether or not a program is successful in reducing homelessness for its clients. A CBR approach to evaluations of homeless interventions must consider structural forces such as housing affordability, income assistance rates, and access to health-care and social supports (Pauly, Wallace \& Perkin 2014).

Findings from this evaluation continue to be integrated into larger efforts to respond to homelessness through presentations to provincial and local policymakers and service providers. In addition, based on the findings of this research, we are working with the shelter staff to incorporate the findings to improve and refine the transitional shelter program and have identified further areas for research. We are continuing our research relationship and thus, have a well-established community-university partnership that will extend into the future.

University-community partnerships committed to the principles of community-based research can function effectively within this reality. Effectiveness can be enhanced by attention to ensuring that research endeavours are driven by important questions of interest to community partners and are methodologically sound without being overly cumbersome or adding to workloads in a sector that often has limited resources. Taking advantage of existing data collection procedures and integrating research into agency or funder data collection processes can reduce duplication and burden but requires ongoing attention to support and training. While there was clear compatibility in terms of researcher and community goals, attention to differing timelines and reporting expectations was important to ensure mutual benefits in the process and achievement of social justice outcomes. 


\section{REFERENCES}

Barrow, S \& Zimmer, R 1999, 'Transitional housing and services: A synthesis', in L Forsburg \& D Dennis (eds), Practical lessons: The 1998 Symposium on Homelessness Research, U.S. Department of Housing and Urban Development and U.S. Department of Health and Human Services, Washington DC.

Baxter, P \& Jack, S 2008, 'Qualitative case study methodology: Study design and implementation for novice researchers', The Qualitative Report, vol. 13 , no. 4 , pp. $544-59$.

Bryant, T, Raphael, D, Schrecker, T \& Labonte, R 2011, 'Canada: A land of missed opportunity for addressing the social determinants of health', Health Policy, vol. 101, no. 1, pp. 44-58.

Canada Mortgage and Housing Corporation 2010, '2006 Census Housing Series: Issue 8 - Households in core housing need and spending at least $50 \%$ of their income on shelter', Research Highlight, Socio-economic Series 10-017.

Canada Mortgage and Housing Corporation 2011, Housing in Canada Online. Based on 2006 census data.

Canada Mortgage and Housing Corporation 2012, 'Rental Market Report: Victoria CMA'.

Cargo, M \& Mercer, S 2008, 'The value and challenges of participatory research: Strengthening its practice', Annual Review of Public Health, vol. 29, pp. 325-50.

City of Victoria 2007, 'Mayor's Task Force on Breaking the Cycle of Mental Illness, Addiction and Homelessness: Report of the Steering Committee', City of Victoria, Victoria, Canada.

Dordick, G 2002, 'Recovering from homelessness: Determining the quality of sobriety in a transitional housing program', Qualitative Sociology, vol. 25, no. 1, pp. 7-32.

Dunn, J, van der Meulen, E, O'Campo, P \& Muntaner, C 2013, 'Improving health equity through theory-informed evaluations: A look at housing first strategies, cross-sectoral health programs, and prostitution policy', Evaluation and Program Planning, vol. 36, no. 1, pp. 184-90.

Eberle, M, Kraus, D, Pomeroy, S \& Hulchanski, D 2001, Homelessness Causes and effects: A profile, policy review and analysis of homelessness in British Columbia, Volume 2, Victoria.

Frankish, C, Hwang, S \& Quantz, D 2005, 'Homelessness and health in Canada: Research lessons and priorities', Canadian Journal of Public Health, vol. 96, suppl. 2, pp. 23-29s.

Gaetz, S, Donaldson, J, Richter, T \& Gulliver, T 2013, The state of homelessness in Canada 2013, Canadian Homelessness Research Network Press, Toronto.

Gaetz, S, Richter, T, Gullivan, T 2014, The state of homelessness in Canada 2014, Canadian Observatory on Homelessness, Toronto.

Green, L \& Mercer, S 2001, 'Can public health researchers and agencies reconcile the push from funding bodies and the pull from communities?', American Journal of Public Health, vol. 91, no. 12, pp. 1926-29.

Hulchanski, J 2009, 'Homelessness in Canada: Past, present, future', keynote address at the Growing Home: Housing and Homelessness conference, University of Calgary, Canada, 18 February. 
Hwang, S, 2001, 'Homelessness and health', Canadian Medical Association Journal, vol. 164 , no. 2 , pp. 229-33.

Hwang, S, 2010, Housing vulnerability and health: Canada's hidden emergency, Research Alliance for Canadian Homelessness, Housing, and Health, Toronto.

Hwang, S, Wilkins, R, Tjepkema, M, O'Campo, P \& Dunn, J 2009, 'Mortality among residents of shelters, rooming houses, and hotels in Canada: 11 year follow-up study', British Medical Journal, vol. 339, p. b4036.

Israel, B, Schulz, A, Parker, E \& Becker, A 1998, 'Review of communitybased research: Assessing partnership approaches to improve public health', Annual Review of Public Health, vol. 19, pp. 173-202.

Lazarus, S, Duran, B, Caldwell, L \& Bulbulia, S 2012, 'Public health research and action: Reflections on challenges and possibilities of community-based participatory research', in J Maddock (ed.), Public health: Social and behavioral health, InTech, accessed 3 January 2015, www.intechopen.com.

Minkler, M \& Baden, A, 2008, 'Impacts of CBPR on academic researchers, research quality and methodology, and power relations', in M Minkler \& $\mathrm{N}$ Wallerstein (eds), Community-based participatory research for health: From process to outcomes, Jossey-Bass, San Francisco, CA.

Minkler, M, Vasquez, V, Tajik, M \& Petersen, D 2008, 'Promoting environmental justice through community-based participatory research: The role of community and partnership capacity', Health Education \& Behavior, vol. 35, no. 1, pp. 119-37.

Minkler, M \& Wallerstein, N 2008, Community-based participatory research for health: From process to outcomes, Jossey-Bass, San Francisco, CA.

Norman, T \& Pauly, B 2013, 'Including people who experience homelessness: A scoping review of the literature', International Journal of Sociology and Social Policy, vol. 33, no. 3/4, pp. 136-51.

Pauly, B, Carlson, E \& Perkin, K 2012, Strategies to end homelessness: Current approaches to evaluation, Canadian Homelessness Research Network Press, Toronto.

Pauly, B, Cross, G, Vallance, K, Wynn-Williams, A \& Stiles, K 2013, Facing homelessness, Greater Victoria Coalition to End Homelessness, Victoria.

Pauly, B, Thompson, D, Kerr Suthin, M, \& Jackson, N 2011, Hungry and homeless in Greater Victoria: 2011 report on housing and supports, Greater Victoria Coalition to End Homelessness, Victoria.

Pauly, B, Wallace B \& Perkin, K 2014, 'Approaches to evaluation of homelessness interventions', Housing, Care and Support, vol. 17, no. 4, pp. 177-87.

Pawson, R \& Tilley, N 1997, Realistic evaluation, Sage, London.

Quigley, J \& Raphael, S 2001, 'The economics of homelessness: The evidence from North America', European Journal of Housing Policy, vol. 1, pp. 323-36.

Raphael, D 2009, Social determinants of health: Canadian perspectives, Canadian Scholars' Press, Toronto.

Reid, C, Brief, E \& LeDrew, R 2009, Our common ground: Cultivating women's health through community based research, Women's Health Research Network, Vancouver. 
Shapcott, M 2009, 'Housing', in D Raphael (ed.), Social determinants of health: Canadian perspectives, Canadian Scholars' Press Inc., Toronto.

Springett, J \& Wallerstein, N 2008, 'Issues in participatory evaluation', in M Minkler \& N Wallerstein, N (eds), Community-based participatory research for health: From process to outcomes, Jossey-Bass, San Francisco, CA.

Statistics Canada 2013, 'Population of census metropolitan areas', accessed 12 December 2013, www.statcan.gc.ca/tables-tableaux/sum-som/ 101/cst01/demo05a-eng.htm.

Stoecker, R 2008, 'Are academics relevant: Approaches and roles for scholars in CBPR', in M Minkler \& N Wallerstein (eds), Community-based participatory research for health: From process to outcomes, Jossey-Bass, San Francisco, CA.

Strand, K 2003, Community-based research and higher education: Principles and practices, Jossey-Bass, San Francisco, CA.

Tsemberis, S \& Eisenberg, R 2000, 'Pathways to housing: Supported housing for street-dwelling homeless individuals with psychiatric disabilities', Pyschiatric Services, vol. 51, no. 4, pp. 487-93.

Wallace, B, Klein, S \& Reitsma-Street, M 2006, Denied assistance: Closing the front door on welfare in $B C$, Canadian Centre for Policy Alternatives \& Vancouver Island Public Interest Research Group, Vancouver.

Wallerstein, N \& Duran, B 2008, 'The theoretical, historical, and practice roots of CBPR', in M Minkler \& N Wallerstein (eds), Community-based participatory research for health, 2nd edn, John Wiley and Sons, San Francisco, CA.

Yin, R 2009, Case study research: Design and methods, 4th edn, Sage, Thousand Oaks, CA. 